\title{
METODE
}

\section{NOVI RAZISKOVALNI PRISTOPI V DRUŽBENI GEOGRAFIJI: PARTICIPATIVNO AKCIJSKO RAZISKOVANJE}

\author{
AVTORJA \\ Dane Podmenik \\ Montinjan 6, SI - 6273 Marezige, Slovenija \\ dane.podmenik@gmail.com

\section{Maks Bembič} \\ Dekani 224, SI - 6271 Dekani, Slovenija \\ maks.bembic@gmail.com
}

DOI: $10.3986 / G V 87207$

UDK: 911.3:001.891

COBISS: 1.02

\section{IZVLEČEK}

Novi raziskovalni pristopi $v$ družbeni geografiji: participativno akcijsko raziskovanje

Participativno akcijsko raziskovanje predstavlja (radikalen) odmik od »konvencionalnih « raziskovalnih pristopov, saj združuje raziskovanje in aktivizem s ciljem reševanja družbenih problemov. Pri tem je ključni poudarek na vzpostavljanju enakovrednega odnosa med raziskovalcem in raziskovanci, ki so vključeni $v$ procese raziskovanja. Medtem, ko lahko v mednarodni geografiji govorimo o "participativnem « obratu, to ne velja za domačo geografijo, saj se participativnemu akcijskemu raziskovanju za enkrat ne posveča večje pozornosti.

\section{KLJUČNE BESEDE}

kritična geografija, participativno akcijsko raziskovanje, participativni proces in metode, aktivizem, reševanje družbenih problemov

\section{ABSTRACT}

New research approaches in human geography: participative action research

We are focusing on the participative action research, which represents a (radical) deviation from "conventional « research approaches. It combines research and activism, with the aim of solving social problems. One of the main characteristics of this approach is building an equivalent relationship between the researcher and the observers (subjects), which are jointly involved in all stages of the research. While we are witnessing the "participative" turn in the international geography, this is not the case in the Slovenia, since there is not a lot of attention dedicated to participative action research.

\section{KEY WORDS}

critical geography, participative action research, participative process and methods, activism, social problems

Uredništvo je prispevek prejelo 30. julija 2015. 


\section{Uvod}

$\mathrm{V}$ (družbeni) geografiji smo priča teoretični in metodološki diverzifikaciji ter posledično uporabi novih pristopov oziroma raziskovalnih metod. Med najbolj »tendenčne« se uvršča tudi participativno akcijsko raziskovanje (Sue in DeLyser 2012; DeLyser in Sue 2014), kar potrjuje naraščajoče število prispevkov s tega področja, med pomembnejšimi omenjamo monografija Participatory Action Research Approaches and Methods: Connecting People, Participation and Place (Kindon, Pain in Kesby 2007). Participativno akcijsko raziskovanje (v nadaljevanju PAR) tako pridobiva širše priznanje znotraj geografske stroke, saj je pred desetletjem ustanovljena delovna skupina participativne geografije leta 2008 pridobila status raziskovalne skupine pri Royal Geographical Society (Kindon 2010).

Slovenska geografija pa PAR (zaenkrat) ne namenja večje pozornosti bodisi v obliki teoretično-metodološke obravnave bodisi empirične uporabe. To potrjuje tudi poizvedovanje po bazah »Cobiss« in "Google učenjak«, saj pod ključnimi besedami »participativno akcijsko raziskovanje« in »participativno raziskovanje«, ni zabeleženega nobenega zadetka s področja geografije. Prav tako, s pomočjo baze "Cobiss«, v fakultetnih knjižnicah z geografskimi oddelki nismo našli niti enega vira, povezanega s PAR. Kot zanimivost lahko dodamo, da se izvod prej omenjene geografske monografije (Kindon, Pain in Kesby 2007) nahaja le v knjižnici Fakultete za socialno delo, Univerze v Ljubljani. Na tem mestu je treba dodati, da med geografi sicer prihaja do (naraščajoče) uporabe "participativnih pristopov«, zlasti povezanih s prostorskim načrtovanjem, vendar le teh ne moremo enačiti s PAR. Zato je glavni namen prispevka osvetliti (teoretična) izhodišča, značilnosti in uporabo PAR v geografiji ter tako spodbuditi diskurz, ki bi odprl prostor za uporabo tega pristopa tudi v slovenski geografiji.

\section{Kratek pregled razvoja PAR}

Korenine PAR izhajajo iz akcijskega raziskovanja, katerega utemeljitelj je bil psiholog Kurt Lewin. Zagovarjal je stališče, da ima znanost praktično funkcijo in da rezultat raziskave ne sme biti le predlog, temveč tudi ukrep, ki bo problem rešil. Akcijsko raziskovanje (v nadaljevanju AR) je definiral kot obliko eksperimentalne raziskave, ki svoja vprašanja rešuje s pomočjo izkušenj skupin, ki se srečujejo $\mathrm{z}$ določenimi težavami. Pri tem je zelo pomemben vzajemen odnos med raziskovalcem in udeleženci, v okviru katerega se ciklično izmenjujeta akcija in refleksija. V sedemdesetih letih 20 . stoletja so družbenokritični družboslovci začeli razvijati nov pristop k AR, ki je temeljil na kritični družbeni teoriji ter je bil usmerjen zlasti v ozaveščanje in politično aktiviranje družbeno prikrajšanih skupin, z namenom spreminjanja družbenih razmer (Mesec 1993). Tako se je PAR, kot ga poznamo danes, uveljavilo zlasti v Latinski Ameriki, Afriki in Indiji. Kot "pionirja « lahko izpostavimo Paula Freira. Slednjega in ostale raziskovalce je vodilo zlasti nezadovoljstvo z zapuščino kolonializma, razvojnimi projekti, vodenimi od zunaj ter prevladujočo pozitivistično raziskovalno paradigmo (Kindon, Pain in Kesby 2007). Vzporedno so se s popularizacijo PAR razvijali tudi novi pristopi. Tako obstajajo številne veje participativnega raziskovanja, ki se v večini primerov konceptualno prekrivajo. V preteklosti je prevladoval pogled, ki je uporabo PAR umeščal (izključno) v manj razvite dele sveta in marginalizirane skupnosti. Danes se PAR vedno bolj uveljavlja tudi v »razvitem« svetu (Kindon in Elwood 2009).

\section{Temelji PAR v geografiji}

V geografiji ima PAR korenine v teorijah radikalne oziroma kritične geografije. Le-ta v veliki meri temelji na delih Marxa in radikalnega geografa Kropotkina, ki sta že v 19. stoletju problematizirala vlogo znanosti pri (ne)zmožnosti reševanja praktičnih oziroma življenjskih problemov. Kritična geografija je pridobila na pomenu ob koncu šestdesetih let prejšnjega stoletja, kot odziv na prevlado od ljudi odtujene, 
družbeno in politično ambivalentne oziroma neangažirane ter preveč kvantitativno usmerjene geografije. Cilj je bil vzpostaviti novo, družbeno odgovorno geografijo, usmerjeno k reševanju konkretnih družbenih problemov. To je zahtevalo večjo družbeno vpetost in angažiranost raziskovalcev, ki pa se je odražala zlasti v radikalizaciji načina pisanja in poučevanja ter okrepljeni vlogi pri načrtovanju in kreiranju politik. Tako je večina (kritičnih) geografov videla lasten prispevek k družbenim spremembam prek (poskušanja) vpliva na oblikovalce politike oziroma centre moči in študente (kot bodoče oblikovalce politik), ne pa v raziskovanju »na ulicah« ter reševanju problemov skupaj z ljudmi (Fuller in Kitchin 2004). V osemdesetih letih so kritični geografi več pozornosti začeli namenjati tudi drugim družbeno kritičnim teorijam, kot so strukturalna teorija, politična ekonomija, realizem in feminizem. Zlasti feministična geografija je velik poudarek dajala vprašanjem, povezanim z reševanjem družbenih problemov v sodelovanju $\mathrm{z}$ marginaliziranimi skupinami, produciranju znanstvenega znanja ter uporabi primernih metod in s tem pomembno vplivala na razvoj PAR v geografiji (Fuller in Kitchin 2004). Devetdeseta leta so prinesla širšo uveljavitev kritične geografije (Peake in Sheppard 2014), hkrati pa je prišlo tudi do različnih pogledov do njene kritične vloge. Mnogi kritični geografi so se pod vplivom prevladujočega postmodernizma posvetili teoretičnemu delu, usmerjenemu v kritiko akademskega prostora in družbe. Kot odgovor na odmik od temeljev kritične geografije in umik v »akademski slonokoščeni stolp«, se je vedno več kritičnih geografov začelo posvečati aktivističnemu raziskovanju (Fuller in Kitchin 2004). Na ta način je prišlo do združevanja znanstvenega dela z aktivizmom, kar je bilo v preteklosti zelo redko. Med geografi sicer lahko najdemo številne na primer prostovoljne delavce, okoljske in družbene aktiviste, vendar jih velika večina (strogo) loči raziskovalno delo od "popoldanskega " aktivizma in družbenega udejstvovanja (Kitchin in Hubbard 1999). Posledično je prišlo do povečanega zanimanja za PAR (Kindon, Pain in Kesby 2007).

\section{Opredelitev PAR}

V literaturi ni enotno sprejete definicije PAR, so si pa pogledi avtorjev glede njegovih glavnih značilnosti in ciljev večinoma zelo blizu. Po najbolj osnovni definiciji povezuje PAR raziskovalce in udeležence raziskave $\mathrm{z}$ namenom skupne opredelitve in reševanja problema (Wadsworth 1998). Tako cilj PAR ni le raziskati, analizirati ali opisati določen družbeni problem, ampak aktivno prispevati k njegovi rešitvi (Pratt 2000). Gre torej za integracijo družbenega raziskovanja, izobraževanja oziroma učenja ter akcije (Hall 2005). PAR je usmerjen v spodbujanje sposobnosti in opolnomočenje (posameznika in skupnosti), razvoj skupnosti, socialno pravičnost, širšo dostopnost in participacijo (Volman, Anderson in McFarlane 2004).

Ključna značilnost in tudi razlika, v primerjavi s »konvencionalnim « raziskovanjem, je v redistribuciji moči preko vzpostavljanja enakovrednega odnosa med raziskovalci (akademskim svetom) in raziskovanci (neakademskim svetom), ki skupaj tvorijo raziskovalno skupino. Pri tem je pomembno poudariti, da PAR temelji na predpostavki, da imajo lokalni ljudje bogata znanja in bi bilo ignoriranje le-teh nesprejemljivo. Zato je velik poudarek na vključevanju lokalnih ljudi v vse faze raziskovanja. Posledično se med udeleženci ustvarja recipročno partnerstvo, ki temelji na participativnem načrtovanju in izvajanju raziskovanja, (neprestanem) medsebojnem učenju in skupnem »lastništvu " nad rezultati raziskav. Na ta način prihaja do obojestranskih koristi za vse vpletene. Raziskovalci imajo priložnost raziskovati izven prevladujočih okvirov in pristopov, prek katerih lahko pridobijo poglobljen vpogled v problematiko ter postanejo akterji družbenih sprememb. »Soraziskovalci« pa imajo možnost aktivnega sodelovanja pri raziskovanju in reševanju problemov, ki zadevajo njih oziroma okolje v katerem živijo (Fuller in Kitchin 2004; Pain 2004).

PAR seveda stremi k čim aktivnejši vključenosti udeležencev v vse faze, vendar pa v realnosti prihaja do različnih stopenj participacije. Najbolj se je uveljavil pogled, ki na stopnjo participacije gleda kot na kontinuum in ne kot na hierarhično lestvico ter priznava veljavnost različnim oblikam in stopnjam 
participacije med samim raziskovalnim procesom (Kindon, Pain in Kesby 2007). Pri nizki stopnji participacije celoten proces bolj ali manj nadzoruje raziskovalec, kar pa ni v skladu $\mathrm{z}$ načeli PAR. S krepitvijo participacije pa se moč in nadzor nad procesom razpršita med člane raziskovalne skupine. $Z$ vidika števila vključenih oseb lahko govorimo o ozki (vključenih le nekaj oseb) in široki (vključenih veliko oseb) participaciji (Cornwall in Jewkes 1995). Vsekakor je pomembno poudariti, da je treba upoštevati pravilo, da o načinu in stopnji participacije lahko (so)odločajo vsi udeleženci (Kindon, Pain in Kesby 2007).

Ena od ključnih značilnost PAR je tudi usmerjenost v »akcijo«, prek katere pride do generiranja in sprožitve družbene spremembe. Po Maguire (1987 v: MacDonald 2012) lahko PAR sproža tri tipe družbenih sprememb, in sicer razvoj kritičnega (samo)zavedanja med člani raziskovalne skupine, izboljšanje življenjskih pogojev za udeležence raziskave in transformacijo socialnih struktur in odnosov. Ločimo tudi različne vrste akcije, glede na usmerjenost (notranja ali zunanja, osebna ali kolektivna), obseg (lokalna ali širše družbena) in pogostost (epizodična ali sistematična).

\section{Proces in metode ter tehnike PAR}

Čeprav za PAR ni predpisanih točno določenih postopkov in korakov oziroma je opredelitev le-teh v domeni raziskovalne skupine, pa naj bi vsak proces temeljil na tako imenovani spirali samorefleksivnih ciklov. Vsak cikel tvorijo naslednji koraki: načrtovanje, akcija in opazovanje procesa ter posledic in refleksija procesa ter posledic. Ti cikli se po potrebi ponavljajo do sklenitve raziskave. Zato je PAR definiran kot cikličen proces. $V$ realnosti proces lahko odstopa od opisanih korakov in se prilagaja okoliščinam. Merilo uspešnosti PAR tako ni v tem ali se udeleženci strogo držijo predpisanih korakov, temveč predvsem $\mathrm{v}$ kolikšni meri razumejo sam proces in položaj, $\mathrm{v}$ katerem delujejo ter se zavedajo napredka v njihovem delovanju (Kemmis in McTaggart 2005). V preglednici 1 so prikazane ključne faze procesa PAR, ki ga predlagajo Kindon in sodelavci (2007).

Preglednica 1: Ključne faze procesa PAR (Kindon, Pain in Kesby 2007).

\begin{tabular}{ll}
\hline faza & aktivnost \\
\hline akcija & $\begin{array}{l}\text { Skupno iskanje in definiranje problema oziroma vsebine raziskave ter sprejemanje časovnih } \\
\text { okvirov raziskave. }\end{array}$ \\
\hline refleksija & Na zasnovo raziskave, etiko, razmerje moči, proces socialnega učenja. \\
\hline akcija & $\begin{array}{l}\text { Vzpostavljanje odnosov; opredeljevanje vlog, odgovornosti in procesov etike; parafiranje } \\
\text { memoranduma o sodelovanju; zasnova procesov raziskave in orodij; razprava in opredelitev } \\
\text { želenih rezultatov ukrepov. }\end{array}$ \\
\hline refleksija & Na raziskovalna vprašanja in zasnovo, delovne odnose, pridobivanje informacij. \\
\hline akcija & $\begin{array}{l}\text { Skupno izvajanje raziskovalnega procesa in zbiranja podatkov; omogočanje vključevanja ostalih; } \\
\text { ocena potrebe po nadaljnjih raziskavah in/ali različnih možnosti ukrepanja. }\end{array}$ \\
\hline refleksija & $\begin{array}{l}\text { Na raziskovalni proces; stopnjo participacije udeleženih; oceno potrebe po nadaljnjih raziskavah } \\
\text { in/ali različnih možnosti ukrepanja. }\end{array}$ \\
\hline akcija & $\begin{array}{l}\text { Načrtovanje aktivnosti ražirjanja rezultatov raziskave, ki zagotavljajo povratne informacije } \\
\text { sodelujočim in vsem ostalim na katere raziskava vpliva. }\end{array}$ \\
\hline
\end{tabular}

Za PAR je značilen pluralizem metod in tehnik. V prvi vrsti je njihova izbira odvisna od članov raziskovalne skupine, narave raziskovalnega problema in okoliščin. Ključno je, da lahko z uporabo izbranih metod in tehnik, člani skupine skupaj zbirajo in analizirajo informacije oziroma podatke ter nato na pod- 
lagi tega prispevajo k rešitvi opredeljenega družbenega ali okoljskega problema (Kindon in Elwood 2009). Ker je PAR vedno tudi študija primera praktičnega odločanja in delovanja, je tu še posebej priporočljiva uporaba metod opazovanja $\mathrm{z}$ udeležbo, intervjuja, skupinske razprave, preučevanja dokumentov ter preučevanja materialnih in nematerialnih proizvodov. Prednost imajo kvalitativne metode, kar pa ne pomeni, da PAR ne omogoča tudi uporabe kvantitativnih metod (na primer anketa). V preteklosti so prevladovale »konvencionalne« tehnike, kot so diskusije, dnevniki, zapisovanje dogodkov, simulacije ter tehnike kritičnih dogodkov in stalnega primerjanja dogodkov (Mesec 1994). Vedno bolj pa v ospredje prihajajo novejše tehnike: video, fotografiranje, mapiranje, diagramiranje, modeliranje, analize trendov in uporaba GIS (Kindon s sodelavci 2007). Slednji temelji na sovključevanju različnih skupin ljudi in lokalnih znanj, z namenom skupne vizualizacije prostora, potreb in virov. Tovrstni podatki so zelo pomembni in uporabni, saj prikazujejo poglobljene informacije o prostoru in družbi, ki velikokrat (z uporabo konvencionalnih pristopov) ostanejo neraziskani. Avtorji navajajo različne prednosti in praktične doprinose uporabe participativnega GIS (PGIS). Poleg krepitve sodelovanja in znanj med ljudmi ter člani različnih organizacij, lahko pripomore tudi k bolj utemeljenemu zagovarjanju stališč, $\mathrm{v}$ nasprotju z razvojnim planom in politikami, ki so v nasprotju s potrebami in pogledi lokalne skupnosti. Omogoča tudi lažje »lobiranje« oziroma prepričevanje predstavnikov občin, investitorjev in drugi za pridobitev sredstev za razvoj skupnosti (Elwood, Feliciano in Gemsin 2007).

\section{Primeri uporabe PAR v geografiji}

Znotraj geografije lahko govorimo o pestrosti uporabe PAR. V nadaljevanju nekoliko podrobneje predstavljamo dva izbrana primera, izvedena v zadnjih nekaj letih. V Novi Angliji, kjer se je ribištvo znašlo pred ekonomsko in okoljsko krizo, je bil izvajan projekt, usmerjen v poglobljeno razumevanje ribiške skupnosti ter njihovih znanj za krepitev vključevanja lokalnih ribičev v procese upravljanja z naravnimi viri in $\mathrm{v}$ spodbudo razvoja lokalne ribiške ekonomije. V proces, ki je temeljil na uporabi metod kartiranja in intervjujev, so bili vključeni zunanji in lokalni strokovnjaki oziroma raziskovalci ter ribiči. Na ta način je prišlo do kartografske re-vizualizacije samega prostora in ribiške skupnosti, kar je odprlo nove poglede ter možnosti za trajnostni razvoj območja. Projekt je pripomogel k temu, da so ribiči re-pozicionirali svojo vlogo znotraj skupnosti in postali aktiven deležnik pri načrtovanju razvoja in varovanju okolja. Rezultati projekta so neposredno vplivali na ustanovitev lokalne mreže ribičev, znanstvenikov in okoljevarstvenikov, katere namen je vzpostaviti model skupnostnega soupravljanja na področju ribištva. Avtorji izpostavljajo tudi pomemben prispevek projekta k pridobivanju novih podatkov, pomembnih za znanost na področju ribištva in upravljanja $\mathrm{z}$ naravnimi viri (Martin in Hall-Arber 2007).

V Chicagu so se povezali univerzitetni raziskovalci, predstavniki razvojnih in nevladnih organizacij ter lokalni prebivalci in zagnali projekt vzpostavljanja skupnostnega participativnega GIS (PGIS). Cilj projekta je bil izgradnja GIS baz, ki bi služile kot orodje za pomoč pri načrtovanju in izvajanju razvojnih aktivnosti lokalne skupnosti. Projekt je vključeval različne metode in tehnike, kot so delavnice, srečanja, (terenska) kartiranja, prek katerih so vzpostavili tudi »mini-laboratorij GIS« in podatkovno knjižnico z bogato bazo prostorskih podatkov. Odziv lokalne skupnosti je bil izreden. Tako so na primer zaključili, da je ponudba raznih aktivnosti in pomoči za starejše prebivalce zelo pestra, medtem pa za mlade, kljub velikim potrebam, ni poskrbljeno. Na podlagi teh ugotovitev so izdelali projektni predlog vzpostavitve mladinskega centra (Elwood, Feliciano in Gemsin 2007).

\section{Kritike in izzivi PAR}

Z naraščajočo popularizacijo PAR se posledično pojavljajo tudi kritike, usmerjene zlasti v vprašanja povezana s participacijo, razporeditvijo moči oziroma nadzorom procesa, idealizacijo lokalnih znanj, 
uporabo metod in znanostjo. Tako na primer Kotharijeva (2001) v PAR vidi »trojanskega konja«, saj naj bi (zunanji) izvajalci na račun (navideznega) vključevanja želeli pridobiti nadzor in moč. Pri tem zmotno prihaja do enačenja PAR s tako imenovanimi participativnimi razvojnimi projekti (na primer projekti Svetovne banke), ki so velikokrat podrejeni interesom kapitala in neoliberalne politike ter nimajo veliko skupnega $\mathrm{z}$ načeli PAR. Z vidika znanstvene verodostojnosti so kritike usmerjene v to, da subjekt in objekt raziskovanja nista neodvisna, da ugotovitev ni mogoče generalizirati ter da ni mogoče zadostiti kriterijem objektivnosti in zanesljivosti. Pri tem zagovorniki PAR odgovarjajo, da gre za pristop z lastnimi kriteriji znanstvenosti, ki jih ni mogoče presojati po kriterijih klasičnega empiričnega raziskovanja (Mesec 1993). Strinjajo pa se, da je treba kritike podrobno preučiti in upoštevati ter iskati načine, kako izboljšati prakse PAR (Kindon, Pain in Kesby 2007).

Uporaba PAR predstavlja tudi velik izziv za same raziskovalce, ki se soočajo zlasti z vprašanji, povezanimi s časovno intenzivnostjo izvajanja tovrstnih raziskav, vklapljanjem v skupnost oziroma pridobivanjem zaupanja s strani lokalnih ljudi, uspešnostjo zagotavljanja participacije, zahtevnostjo koordinacije raziskovalne skupine, izbiro in uporabo primernih metod ter nerazumevanjem in nepriznavanjem s strani širše raziskovalne sfere (MacDonald 2012). Zato številni avtorji opisujejo svoje praktične izkušnje in probleme s PAR ter s tem spodbujajo ostale raziskovalce (na primer Klocker 2012).

\section{Sklep}

PAR je proces, ki združuje paleto participativnih pristopov $\mathrm{k}$ akcijsko usmerjenemu raziskovanju. Ključni cilj je usmerjen v spodbujanje kolektivne akcije, kar pa ne pomeni, da uporaba PAR ne prinaša tudi novih teoretičnih in znanstvenih dognanj. PAR se vedno bolj uveljavlja v »razvitem « svetu in tudi v geografiji. Med slovenskimi geografi smo sicer priča naraščajoči uporabi participativnih pristopov (zlasti gre za razne delavnice $\mathrm{z}$ različnimi lokalnimi deležniki), na primer pri projektih prostorsko-razvojnega načrtovanja (Razpotnik Visković, Urbanc in Nared 2009; Nared s sodelavci 2015) in upravljanja s kulturno dediščino na podeželju (Bole s sodelavci 2014; Nared in Razpotnik Visković 2014), ki pa jih ne moremo enačiti s PAR. To utemeljujemo iz različnih vidikov PAR. Iz navedenih virov je moč sklepati, da ni prišlo do višje stopnje participacije v smislu enakopravne in aktivne soudeležbe lokalnega prebivalstva pri vseh fazah raziskovanja, ampak je šlo za vključevanje lokalnega prebivalstva le v posamezno (že vnaprej določeno) fazo. Hkrati tudi ni razvidno, če in kakšne neposredne koristi so imeli lokalni prebivalci od participacije. Ali so njihova mnenja, pobude, ideje in podobno (p)ostale le »mrtva črka na papirju « ali pa je dejansko prišlo do pozitivnih in konkretnih sprememb oziroma rešitve problemov v okolju? Tako na primer Nared s sodelavci (2015) med ključnimi rezultati projekta navajajo, da so lokalni deležniki prek izvedenih delavnic prepoznali probleme in priložnosti ter vizijo razvoja regije, kar je bila tudi podlaga za pripravo Inovativne strategije trajnostnega razvoja Občine Idrija (Nared 2011). Na tem mestu prihaja do ključne razlike, saj PAR, z vidika akcije, zahteva še korak naprej v smeri, da se prek izvedbe procesa (identificirani) problemi (v sodelovanju) tudi rešujejo v praksi. Sklenemo lahko z ugotovitvijo, da je med slovenskimi geografi sicer prisotnega veliko družbenega in okoljskega aktivizma, ki pa (za enkrat) bolj ali manj ostaja ločen od raziskovalnega dela. Zato vidimo potrebo po integraciji PAR v slovensko geografijo, kar bi doprineslo h krepitvi družbene vloge in pomena geografije.

Zahvala: Članek je nastal v okviru doktorskega študija, ki ga delno sofinancira Evropska unija, in sicer iz Evropskega socialnega sklada. Sofinanciranje se izvaja v okviru Operativnega programa razvoja človeških virov za obdobje 2007-2013, 1. razvojne prioritete Spodbujanje podjetništva in prilagodljivosti; prednostne usmeritve 1. 3: Štipendijske sheme. 


\section{Viri in literatura}

Bole, D., Šmid Hribar, M., Kozina, J., Pipan, P. 2014: Sinergija kulture in turizma za razvoj podeželskih območij. Ljubljana.

Cornwall, A., Jewkes, R. 1995: What is participatory research? Social Science and Medicine 41-12. Amsterdam. DOI: http://dx.doi.org/10.1016/0277-9536(95)00127-S

DeLyser, D., Sui, D. 2014: Crossing the qualitative-quantitative chasm III. Enduring methods, open geography, participatory research, and the fourth paradigm. Progress in Human Geography 38-2. Thousand Oaks. DOI: http://dx.doi.org/10.1177/0309132513479291

Elwood, S., Feliciano, R., Gemsin, K. 2007: Participatory GIS, the Humboldt/West Humboldt Park Community GIS Project. Participatory Action Research Approaches and Methods: Connecting People, Participation and Place. Abingdon.

Fuller, D., Kitchin, R. (ur.) 2004: Radical theory/critical praxis. Academic geography beyond the academy? Radical Theory, Critical Praxis, Making a Difference Beyond the Academy. Victoria.

Hall, L. B. 2005: In from the cold. Reflections on participatory action research from 1970-2005. Convergence 38-1. Thousand Oaks.

Kemmis, S., McTaggart, R. 2005: Participatory action research. Communicative action and the public sphere. The SAGE Handbook of Qualitative Research. London.

Kindon, S. 2010: Participation. The SAGE Handbook of Social Geographies. Los Angeles.

Kindon, S., Elwood, S. 2009: Introduction: More than methods - reflections on participatory action research in geographic teaching, learning and research. Journal of Geography in Higher Education 33-1. London. DOI: http://dx.doi.org/10.1080/03098260802276474

Kindon, S., Pain, R., Kesby, M. (ur.) 2007: Participatory Action Research Approaches and Methods: Connecting People, Participation and Place. Abingdon.

Kitchin, R. M., Hubbard, P. J. 1999: Research, action and critical geographies. Area 31-3. New Jersey.

Klocker, N. 2012: Doing participatory action research and doing a PhD: words of encouragement for prospective students. Journal of Geography in Higher Education 36-1. Abingdon. DOI: http://dx.doi.org/ 10.1080/03098265.2011.589828

Kothari, U. 2001: Power, knowledge and social control in participatory development. Participation: The New Tyranny? London.

MacDonald, C. 2012: Understanding participatory action research: A qualitative research methodology option. Canadian Journal of Action Research 13-2. North Bay.

Martin, K., Hall-Arber, M. 2007: Environment and development: (Re)connecting community and commons in New England fisheries. Participatory Action Research Approaches and Methods: Connecting People, Participation and Place. Abingdon.

Mesec, B. 1993: Akcijsko raziskovanje med socialnim inženirstvom in revolucionarnim aktivizmom. Socialno delo 32, 1-2. Ljubljana.

Mesec, B. 1994: Model akcijskega raziskovanja. Socialno delo 33-1. Ljubljana.

Nared, J. (ur.) 2011: Inovativna strategija trajnostnega razvoja Občine Idrija. Elaborat, Geografski inštitut Antona Melika ZRC SAZU. Ljubljana.

Nared, J., Razpotnik Visković, N., Cremer-Schulte, D., Brozzi R., Cortines Garcia, F. 2015: Archieving sustainable spatial development in the Alps through participatory planning. Acta geographica Slovenica 55-2. Ljubljana. DOI: http://dx.doi.org/10.3986/AGS.1631

Nared, J., Razpotnik Visković, N. (ur.) 2014: Managing Cultural Heritage Sites in Southeastern Europe. Ljubljana.

Peake, L., Sheppard, E. 2014: The emergence of radical/critical geography within North America. An International E-Journal for Critical Geographies 2014-13. Medmrežje: http://www.geog.ucla.edu/ sites/default/files/users/esheppard/Peake\%26Sheppard\%20ACME\%202014.pdf (16. 8. 2014). 
Pain, R. 2004: Social geography: Participatory research. Progress in Human Geography 28-5. Thousand Oaks. DOI: http://dx.doi.org/10.1191/0309132504ph511pr

Pratt, G. 2000: Participatory action research. The Dictionary of Human Geography. Oxford.

Razpotnik Visković, N., Urbanc, M., Nared, J. 2009: Prostorska in razvojna vprašanja Alp. Georitem 12. Ljubljana.

Sui, D., DeLyser, D. 2012: Crossing the qualitative-quantitative chasm I: Hybrid geographies, the spatial turn, and volunteered geogrraphic information (VGI). Progress in Human Geography 36-1. Thousand Oaks. DOI: http://dx.doi.org/10.1177/0309132510392164

Wadsworth, Y. 1998: What is participatory action research? Action Research International. Medmrežje: http://www.aral.com.au/ari/p-ywadsworth98.html (1.8.2014).

Volman, R. A., Anderson, T. E., McFarlane, J. 2004: Canadian Community as Partner. Philadelphia.

\section{Summary: New research approaches in human geography: participative action research}

(translated by the authors)

In the last few years we have been witnessing a theoretical and methodological diversification in geography. Among the recent trends we can also find the Participative action research (PAR). The origins of PAR derive from the action research, which is based on the assumption, that science must have a practical function as well as a theoretical one. PAR represents an epistemological challenge to scientific positivism, because it supports the thesis that science should not only understand the world, but also contribute to make it better (Mesec 1993). In geography PAR founds its roots in the theories of critical geography, which developed in the 1960s as a reaction to the predominant peopleless quantitative geography. The objective was to establish a new, human geography, more oriented towards society and actual social problems. The nineties brought a wider recognition of critical geography and more critical geographers started to devote themselves to activism research. Consequently, the interest in PAR methods began to increase (Fuller and Kitchin 2004).

PAR is a combination of social research, learning and action, with the aim of social change. It is not only about exploring, analyzing or describing a particular social problem, but about how to actively contribute to its solution. One of the key characteristics of PAR and the main difference between PAR and the conventional research is the equal relationship between the researcher and the observed (subjects). They form a research group, which is jointly involved in all stages of the research. The process creates a mutual partnership inside the research group through participative planning and implementation of the project, (constant) interactive learning and joint ownership of the research results (Fuller and Kitchin 2004; Pain 2004). The second key characteristic of PAR is focusing on action, which leads to social change. Although the process of PAR is not precisely specified, all the steps are part of the so called self-reflective spiral. Each cycle consists of: planning, action and reflection on the process and results. If necessary, the group repeats these cycles till the end of the research, therefore PAR is defined as a cyclic process (Kemmis and McTaggart 2005). Usually PAR uses several different methods and techniques. First and foremost the choice depends on the members of the research group and on the nature of the research (Kindon and Elwood 2009). Qualitative methods are more frequent, but quantitative methods, like surveys, are also used. The most common methods are: observation and discussion inside the group, interviews, study of documents, material and immaterial products ... Among the most frequently applied techniques there are: group discussion, official records, diaries, role play, simulations and others (Mesec 1994). More recently researchers are using new techniques like videos, photography, diagrammatic reasoning, modeling, trend analysis and GIS (Kindon et al. 2007). In geography PAR is used in various fields. In this article were presented two cases, which contributed to the community development. 
The increased popularity of PAR brought to recognition more critical views as well. Some critics are pointing out that PAR is in many ways misleading, since (outside) contractors under the pretend of (virtual) integration want to obtain control and power over local communities. It should be emphasized that in many cases erroneously comes to compare PAR with the so called "participatory" development projects (such as the World Bank projects), which are actually often subordinated to the interests of capital and neo-liberal policies and have little in common with the principles of PAR. From the perspective of scientific credibility, the critics allege that in PAR findings cannot be generalized and it is not possible to meet the criteria of objectivity and reliability. In response to those critics the PAR proponents argue that this approach has its own criteria of scientific value, which cannot be assessed according to the criteria of conventional empirical researches. Through the implementation of PAR, the researchers are faced with different challenges. As the most acute, the authors highlight the challenges, associated with: the timing intensity of the implementation of PAR, getting involved in the local community, gaining the trust of local people, the participation rate, the complexity of the coordination in the research team, selecting and applying appropriate methods and techniques and misunderstanding and lack of recognition by the wider academic sphere.

In Slovenian geography there is not a lot of attention dedicated to PAR. Although there are a lot of activists among geographers, activism (mainly) remains separate from the academic and research work. We see the need for integrating PAR in the Slovenian geography, which would also contribute to strengthen the social role of geography. 
